\title{
LA PARROQUIA DE SAN MIGUEL DE ALLENDE
}

\section{Mina Ramírez Monies}

La Iglesia Católica, civilizadora de Améri. ca y productora de su arte dejó su huella, hermosa y perdurable, en San Miguel, haciendo de su paisaje ese mosaico de torres y cúpulas que caracterizan toda visión colonial mexicana.

FRANCISCO DE LA MAZA

La villa de San Miguel el Grande, hoy de Allende, debe su fundación a los frailes franciscanos, especialmente a fray Juan de San Miguel, quienes dotados de un ferviente celo apostólico dejaron la simiente de la fe cristiana entre las tribus indígenas de otomíes, huachichiles y chichimecas que, como bien dice Francisco de la Maza: “...pululaban por esos montes y cañadas... sin dejar... ciudades ni poblados notables, por medio de los cuales pudiéramos hacer conjeturas sobre sus historias y costumbres..." 1

Un documento que estuvo en poder del cronista franciscano Félix de Espinosa (información presentada en Xichú, 15 de octubre de 1597), deja ver que las primeras comunidades que poblaron San Miguel, lo hicieron cerca de $1547 \mathrm{y}$ la tradición considera el acontecimiento cinco años más temprano. Tampoco se ponen de acuerdo los historiaciores en cuanto a la denominación del pueblo, algunos lo llaman primero Yzquinapan y otros directamente San Miguel, lo primero tiene su origen en la leyenda y lo segundo se debe a la existencia de una iglesia, cuya advocación era la de ese arcángel. En ocasiones se agregaba "de los chichimecas", y en otras "de los otomíes", más tarde "el Grande" y en la actualidad se le conoce con el apellido de un prócer de la Independencia, Ignacio Allende.

En 1555 el virrey Luis de Velasco expidió título de villa a San Miguel e hizo nombramientos de autoridades gubernamentales, así españolas como indígenas. Tal vez de esta misma fecha o de alguna cercana, data el establecimiento del presidio. ${ }^{2}$

Es difícil hablar con seguridad del progreso económico del pueblo de

1 Francisco de la Maza, San Miguel de Allende, México, Frente de Afirmación His. panista, A. C., 1972, p. 9

2 Ibidem, p 11-13. 
San Miguel durante los dos primeros siglos de la Colonia, debido a la escasez de documentos, en ocasiones, es posible comprobar la bonanza de un sitio por las obras que en él se realizaron. Si este planteamiento fuera válido en nuestro caso, diríamos que la prosperidad sanmiguelense se dio hasta el siglo xvin, es decir corrió paralela con el auge alcanzado por la Nueva España en ese siglo.

Salvo dos o tres edificios eclesiásticos de escasa impoitancia, las demás construcciones civiles y religiosas de San Miguel fueron edificadas en pleno siglo xviII. Los frailes franciscanos habían hecho iglesia desde la fundación de la villa y construido la del tercer orden en el siguiente siglo mas éstas sólo muestran la necesidad del clero para celebrar el culto y administrar los sacramentos, y no son prueba de una riqueza agrícola, ganadera o de gran producción en los obrajes.

También hubo iglesia parroquial en esta villa desde el siglo xvi, ésta dependía del obispado de Michoacán, su erección data de 1564 y la construcción corresponde a la misma centuria. ${ }^{3} \mathrm{El}$ edificio era de planta rectangular, como la mayoría de sus contemporáneos, medía diez y media varas de ancho por cincuenta y una de largo; sus paredes eran de piedra, de la que llamaban "pelada", carecía de contrafuertes, por lo que en el siglo xvir se reforzó con arbotantes para evitar el desplome. La cubierta erà de madera, debió haber tenido un espléndido artesonado a la manera mudéjar, como muchos hubo en las iglesias de aquel obispado. Adosada al templo debió haber estado la capilla de Nuestra Señor a de la Soledad, de la que habla el arquitecto Marcos Antonio Sobrarias al practicar un reconocimiento a la iglesia en $1690^{4}{ }^{4}$

La ruina que amenazaba la techumbre y el dictamen de Sobrarias fueron factores que influyeron para sustituirla, pero sobre todo el deseo de transformar un edificio viejo, útil entonces, por otro de mayor lucimiento que satisfaciera las aspiraciones del clero y de una élite, ambas clases generadoras de un potencial económico, capaz de llevar a cabo tal empresa.

Antes de iniciarnos en la construcción de esta parroquia, está bien recurrir al origen y función de estos edificios eclesiásticos, a la importancia que cobraron durante los siglos xviı y xvir en la Nueva España

3 Ibidem, p. 27 “ . . se construyó la primera iglesia hacia los años de 1578 pues según dicen las Ordenanzas de ese año, a los indios que robasen ganado de españoles se les condenaba por los dueños, el tiempo que les pareciere en el edificio de la iglesia de la villa de San Miguel que al presente se edifica". apud, Archivo General de la Nación, Ordenanzas, vol. 2, f. 220.

4 Archivo General de la Nación, Reales cédulas duplicados, vol. 5̆5, fs, 312-313. 
y finalmente a su tipo arquitectónico. En cuanto a lo primero, es bueno recordar que en los inicios de la Iglesia Cristiana, se usó el término parroquia en el mismo sentido que diócesis; en el siglo rv, además de coexistir ambos vocablos, al primero se le consideró como la parte de diócesis adonde se enviaba un clérigo para administrar sacramentos; más adelante la diócesis se dividió en parroquias sin una delimitación establecida y posterior al Concilio de Trento, se asignaron límites fijos a cada parroquia.

Las funciones correspondientes a estas iglesias fueron y son las de impartir los sacramentos y dar pasto espiritual a la feligresía. Durante el siglo xvi, en los texritorios del Nuevo Mundo, descubiertos por España, la conquista espiritual fue confiada, casi exclusivamente, a las órdenes religiosas, a quienes se concedieron facultades para ejercer funciones parroquiales. La rivalidad del clero secular se hizo patente a finales de ese siglo en la Nueva España, pasión que propició el arrebato de dichas funciones a las órdenes monacales. A mediados de la siguiente centuria los clérigos se habian apoderado de la mayoría de las parroquias y el número de obras arquitectónicas de este tipo fue más abundante, ya que las limosnas, concesiones y mano de obra que en el siglo xvr había servido para hacer conventos, ahora se destinaban a edificar parroquias, visitas de éstas y catedrales. El auge económico y la explosión demográfica del siglo xvin, permitieron el florecimieinto de numerosas construcciones religiosas, muchos edificios fueron reconstruidos y otros se iniciaron y concluyeron. La ornamentación alcanzó su máximo esplendor y el clero secular y regular vieron satisfechos sus deseos, ejemplos de ellos son las magnificas parroquias de Chihuahua y Zacatecas o las iglesias de San Agustín y San Francisco en Querétaro, sólo por mencionar algunos.

El tipo arquitectónico de los edificios parroquiales es bien conocido por todos, no tiene mayor particularidad en su planta, que cualquiera otra iglesia de religiosos de la época que se trate. Las variantes suelen estar en las dependencias, ya que las funciones administrativas de cada parroquia requieren de dos oficinas más: el cuadrante y el archivo.

Proseguiremos nuestro estudio respecto a la construcción de la aciual parroquia sanmiguelense, en 1690 el cura don Francisco de la Fuente Arámburu y el justicia mayor Pedro Morillo Velarde, a nombre propio y de la villa denunciaron las "ruinas" en que se hallaba el templo principal de San Miguel, aducían que los novenos de los diezmos habían sido concedidos desde la erección y de manera perpetua, para la fábrica 
material de la parroquia Los efectos paraban en distintas personas del obispado, por lo que solicitaban al virrey que dichas cantidades fueran requeridas y con ellas se labrase iglesia de nuevo.

Atento a estas súplicas, el virrey conde de Galve, ordenó al maestro de arquitectura y alarife Marcos Antonio Sobrarias, 5 vecino de la ciudad de México, ". . para que junto con otro [maestro] de dicha villa, viesen y reconociesen la dicha iglesia, el estado en que se hallaba y ruina que amenaza[ba], y si el estado que tenía era capaz de reparo o aderezo o si necesitaba de sacarla de cimientos..." 6

El 8 de marzo del mismo año, el arquitecto Sobrarias, junto con Salvador Gómez, oficial de alarife, vecino de Querétaro, ${ }^{\top}$ y Juan Ximénez, oficial de carpintero, y en presencia del cura Francisco de la Fuente Arámburu y del licenciado Francisco García de León, dio su parecer, corroborado más tarde por oficiales y asistentes, que es el siguiente:

... y en obedecimiento de lo mandado por su excelencia, hice catas en diferentes partes de arriba de la tijera, donde están los tirantes y en lo cual hallé todas degolladas y podridas, tanto que se sacaron los pernos que atraviesan planchas y tirantes, y los canes todos más colgados, y para verificar si tenía alguna fuerza para resistir los dichos tirantes, hornagué con una reata uno de ellos y al primer vaivén se biscorneó más de una cuarta del centro del tirante, y las barbillas de las alfardas, todas las más podridas y desmentidas por la parte de arriba en el nudillo y colgadas por la parte de abajo, algunas por estar podridas la solera donde estriba, que sólo se está sosteniendo con el dicho nudillo, con notable riesgo, sin que a ello se le pueda poner ningún apuntalado, trincas ni tornapuntas, por lo cual, habiendo reconocido el riesgo tan evidente que está amenazando la techumbre de la tijera, que por las paredes, aunque no tienen los cimientos que debieran tener, ni estribos, sino son dos arbotantes que están recién hechos, no amenazan el riesgo que la dicha techumbre, por cuya razón hice notorio al dicho justicia mayor y beneficiado, y a todos los vecinos, no entrase ninguna gente en la iglesia, antes si, era de parecer se sacase su divina Majestad. Que hay una capilla de Nuestra Señora de la Soledad, donde puede estar su divina Majestad, en interin que vuestra

5 Nacido aproximadamente en 1646 , comenzamos a tener noticia de su actuar profesional desde 1682, fecha en que fue veedor de su gremio. Durante los años 1683, 1684, 1686 y 1687 sabemos que presentó varios proyectos y reconocimientos de casas y conventos de la ciudad de México: Varii, "Notas para una guía de artistas y artesanos de la Nueva España", en Boletin de Monumentos Históricos, INAH, núms. 1, 4, 5, p. 70; 93-94 y 84 respectivamente; A. G. N., Templos y conventos, caja 10, rol. 61. Participó también en la obra del desagüe. Dato proporcionado por Martha Fernández.

$6 \mathrm{~A} . \mathrm{G} . \mathrm{N} .$, Reales cédulas duplicados, vol $55, \mathrm{f} .311 \mathrm{v}$

7 Ibidem 
excelencia determina lo que fuere servido, y es necesario para el desbarato de dicha tijera, mucha disposición porque no sucedan algunas desgracias, y las dos paredes de los dos lados donde estriban las alfardas están desplomadas poco menos de una sesma y la una de ellas cuarteada, y la otra que pareció estar buena en el taladro que hice, reconocí no estar las mezclas suficientes, ni su macizado como podía estar, y la piedra con que están fabricadas ser de ninguna unión, porque es piedra dura toda ella, la cual Ilamamos en nuestro arte pelada, que es como el guijarro que se cría en los ríos.

$Y$ en otra cata que hice en la pilastra del arco de la capilla mayor, reconocí estar sin cimiento, ni talón, ni cadena, y es la causa que se haya sumergido por la parte de abajo, por diferentes partes la pilastra y el arco, pero lo que está amenazando hoy al presente, riesgo evidente, es sólo la dicha tijera, y esto es todo lo que hallo y todo mi leal saber y entender, según el estado en que hallo la dicha iglesia, por lo cual puse en ejecución el hacer la planta que su excelencia manda. Y para elegir su tamaño, ancho y largo, medí la que hoy está y tuvo por su ancho diez varas y media, y por su largo cincuenta y una varas. $Y$ ver el mucho concurso de gente que va a oir misa los días de fiesta y días festivos, y por lo que me han informado. Por cuya razón puse en once varas de ancho la dicha planta y cincuenta y cinco de largo, que la media vara que excedí en su ancho es por las pilastras que lleva y no poderle quitar nada de largo, que son de las cincuenta y cinco varas. Y para asegurar su fábrica de ella, le eché su crucero que es la obra más fuerte y permanente que hay en el arte y más habiendo yo reconocido el material ser tan pesado, como es el que hay en esta villa, sin haber otro de que poderse valer, antes soy de parecer que el género de bóvedas que se ejecutaren en la dicha planta sean hornacinas, para su mayor permanencia y facilidad de ejecutar, sin tanto gasto como las otras, por cuya razón va ejecutada la planta, superficie que me parece será permanente, porque aunque se pudieran hacer bóvedas en la iglesia que hoy está, era menester echar contracimientos y cadenas y rebajar sus paredes. Sólo me desanima la poca unión que han de tener, por lo que tengo referido y ser poca la diferencia de reedificación a edificarla de nuevo, y con esa quedará toda unida y bien plantada, pues la que hoy está, está mal plantada, causa también de su ruina.

$Y$ habiendo hecho las diligencias del material que hay en esta villa, hay mejor piedra para su edificación que tendrá más unión, con un poco más de costa.

$\mathrm{Y}$ habiendo hecho las diligencias de todos los materiales y distancia que hay de los parajes donde están, para ver poco más o menos lo que podrá costar, y por lo que me han informado los habitadores de esta villa, según las compran, hallo costará cincuenta y ocho mil pesos, poco más o menos, haciéndose la obra llana, sin mucho adorno de portadas, cornisamentos y adorno de toda ella. Y esto que lleva dicho 
dijo ser la verdad y lo que siente, so cargo del jutamento que tiene hecho, en que se afirmó y ratificó y dijo ser de edad de cuarenta y seis años, poco más o menos. Y lo firmó conmigo ảicho alcalde mayor y los testigos de mi asistencia, estando presentes el capitán don Antonio de Urtusástigui, Santiago de Retis, don Antonio de Vargas y Pedro Madera y todos los más vecinos de esta villa que se hallaron presentes a todo lo referido.

\section{Marcos Antonio Sobrarias ${ }^{8}$}

El virrey dio su mandamiento el 15 de julio siguiente, para que Sobrarias se encargara de ejecutar la obra, conforme a la traza que había señalado en su primera visita a la villa. El salario asignado le fue tasado por el maestro mayor de obras de la capital del virreinato, Cristóbal de Medina Vargas, y lo hizo en cantidad de 1,460 pesos anuales, además de 300 que recibiría por el tiempo que invirtió en su viaje a San Miguel y por la traza que dio para la nueva obra. ${ }^{9}$ La administración correría a cargo del alcalde mayor en turno, quien recibiría los caudales proporcionados por los oficiales de la Caja Real de Guanajuato, además el alcalde tendría la obligación de cuidar que la obra adelantase todo lo posible y fuese con toda perfección, duración y permanencia. ${ }^{10}$

El arquitecto Sobrarias aceptó el nombramiento del virrey para maestrear la obra y el salario asignado "... aunque dicha cantidad no es la que se ha dado a otros maestros...", pedía por tanto ayuda de costa para trasladarse y llevar consigo a su familia...

...y en atención a que dicha obra es por mi cuenta y riesgo, se ha de servir vuestra excelencia, asimismo, que los oficiales hayan de ser de mi satisfacción y no otros algunos, por los inconvenientes que pueden resultar y porque si cayera enfermo no se entienda que pare mi salario, teniendo oficiales de toda mi satisfacción, por todo lo que a vuestra excelencia pido y suplico, así lo provea y mande, en que recibiré merced de la grandeza de vuestra excelencia. ${ }^{11}$

También pidió a la autoridad virreinal, poder encargarse de otras obras que se ofreciesen en la villa sin menoscabo de la principal. El virrey concedió la ayuda de costa para el traslado de su familia, así como el abo-

SIbidem, fs. 312-313.

9 Ibidem, fs, 318.319 .

10 Ibidem, fs. 314-315.

11 Ibidem, f. 340v. 
no de su salario en caso de enfermedad temporal, más le negó su participación en otra obra que no fuese la parroquial. ${ }^{12}$

Durante dos años Sobrarias trabajó en la construcción del templo, en septiembre de 1692 escribia al virrey "... que dicha iglesia se halla casi toda luneteada, con su cornisa y encapitelada y un arco toral y bóveda del coro y bautisterio decimbrada..." 13 Para esa fecha el dinero escaseó, pues el producto de los novenos, destinado a ese fin, dejó de recaudarse por haberse promovido al alcalde mayor Diez de la Mora. El sucesor en el cargo, capitán Pedro de la Barrera, notificó al arquitecto Ia orden de suspensión de la obra.

Tal situación vino a perjudicar la construcción del templo y el salario de los obreros. Sobrarias se trasladó a la ciudad de México para exigir el pago de una labor que no se detenía por incumplimiento suyo. Por mandamientos de 1696, 1697 y 1698, el virrey ordenó al alcalde de San Miguel el Grande, diese al maestro de la fábrica lo que se le adeudaba, y ordenaba asimismo la continuación de la obra " ${ }^{14}$ En abril de 1697 el fiscal de la Audiencia de México informaba que el obispo de Michoacán había nombrado a otro maestro para concluirla, sin embargo parece que la sustitución no se hizo antes del gobierno del siguiente virrey, pues en 1698 se le compele a Sobrarias para que pase a la villa de San Miguel a proseguir la obra. ${ }^{15}$

El virrey, duque de Alburquerque, debió haber nombrado al nuevo arquitecto en los inicios de su gobierno, esta vez el elegido fue Juan Antonio de Guzmán, maestro mayor de su arte, a quien se le dio un salario de veinte reales diarios, ${ }^{16}$ cantidad ínfima, si se le compara con los cuatro pesos que ganaba el maestro anterior. Tenemos noticias también del salario de los oficiales y peones, los primeros ganaban seis reales y los segundos dos; entre los oficiales podemos citar a Matheo Giraldo, Salvador de Mendoza, Alonso y Gabriel Correa, Felipe Claudio, Nicolás González, Juan Miguel, Ignacio Guerrero, Juan de Santiago, ${ }^{17}$ Juan Agustín, Nicolás Martín, Salvador Muñoz, Miguel Gerónimo, Bartolomé

12 Ibidem, f. 341

13 Ibidem, f $369 \mathrm{v}$.

14 Ibidem, vol. 63, fs. 33-34; vol. 42, exp. 131, fs. $61 \mathrm{v}-63$ y $\exp$. 150, fs. 7 Iv-72

15 Ibidem, vol 42 , exp. 150, fs. 71v-72.

16 A G. N, Iglesia, vol único.

17 Es probable que sea el mismo Juan de Sanjtiago que reconoció la obra de la catedral de Valladolid en 1671: Mina Ramírez Montes, La catedral de Morelia (documentos: para su historia) en prensa.. 
Joseph, Joseph Boronda, Luis de Luna, Joseph Martín y Antonio Villegas, 18

Marcos Antonio Sobrarias regresó a la capital novohispana. Reconoció en 1702, junto con los maestros de arquitectura Felipe de Roa, Felipe de los Santos y Ávila y Pedro de Arrieta, la obra de la catedral metropolitana. ${ }^{19}$ Interwino en las obras de reedificación del palacio real, que se hicieron a principios del siglo xuII, donde colaboró en el diseño de la planta hecha en 1709, al lado de afamados colegas suyos. ${ }^{20}$

Dejaremos a Sobrarias, a quien parece que la fortuna le favoreció al retornar a la capital, para volver con el tema que nos ocupa: en 1705 se comprometió Juan de Vargas, cura del lugar, a poner en la obra cierta cantidad de piedras de tezontle a su costa, para cerrar bóvedas, poner basas de torres y otras para los santos de la portada. ${ }^{21}$ Un año después estaba concluida una torre y la otra se estaba haciendo. ${ }^{22}$ Para el adorno de éstas se cncargaron unas pirámides de barro vidriado al maestro ollero Diego García. ${ }^{23}$

Para 1709 la fachada estaba terminada, el maestro que dirigía la obra también se comprometió a labrar las esculturas que se colocarian en los nichos, de ellos nos habla el recibo que otorgó al alcalde el 5 de enero de ese año:

... Juan Antonio de Guzmán, maestro mayor de arquitectura y vecino de esta villa, a quien doy fe conozco, otorga haber recibido del señor capitán don Juan de Torres Camberos, alcalde mayor de ella y juez superintendente de la fábrica material de la iglesia parroquial de ella, ciento diez pesos en reales, por los mismos que montaron la hechura de tres santos de piedra de cantería, de a dos varas y ochava de alto para la portada de dicha iglesia y son: el señor San Pedro, San Pablo y el señor San Miguel, los cuales conchavó con dicho señor alcal-

18 A. G. N., Iglesia, vol, único, fs. $87 \mathrm{v}-113 \mathrm{v} ; 161-182$ y $429-438$.

19 A. G. N., Reales cédulas duplicados, vol. $63, \mathrm{fs} 66 \cdot 67 \mathrm{v}$

20 Martha Fenández Garcia, Maestros mayores de arquitectura, en la ciudad de México en el siglo XVII, México, tesis Facultad de Filosofía y Letras, UNAM, 198I, p. 228-232, 258-259.

21 A. G. N., Iglesia, vol único, exp. 4, f 115

22 El obispo de Michoacán decía en carta de mayo de 1743: "Sólo puedo testificar que después de perfecta la iglesia y sacristía y no habiendo sitio en qué extenderse con la fábrica se empezó y acabó otra torre, desigual a la que se había hecho primero, sirviendo las dos para afearse mutuamente...": Francisco de la Maza, op. cit, p. 30, apud. A. G. N, Hospitales, vol. 51, exp. 5, f, 62

${ }_{23}$ A G. N, Iglesia, vol único, exp. 4, f. 127 
DOI: http://dx.doi.org/10.22201/iie.18703062e.1986.55.1271

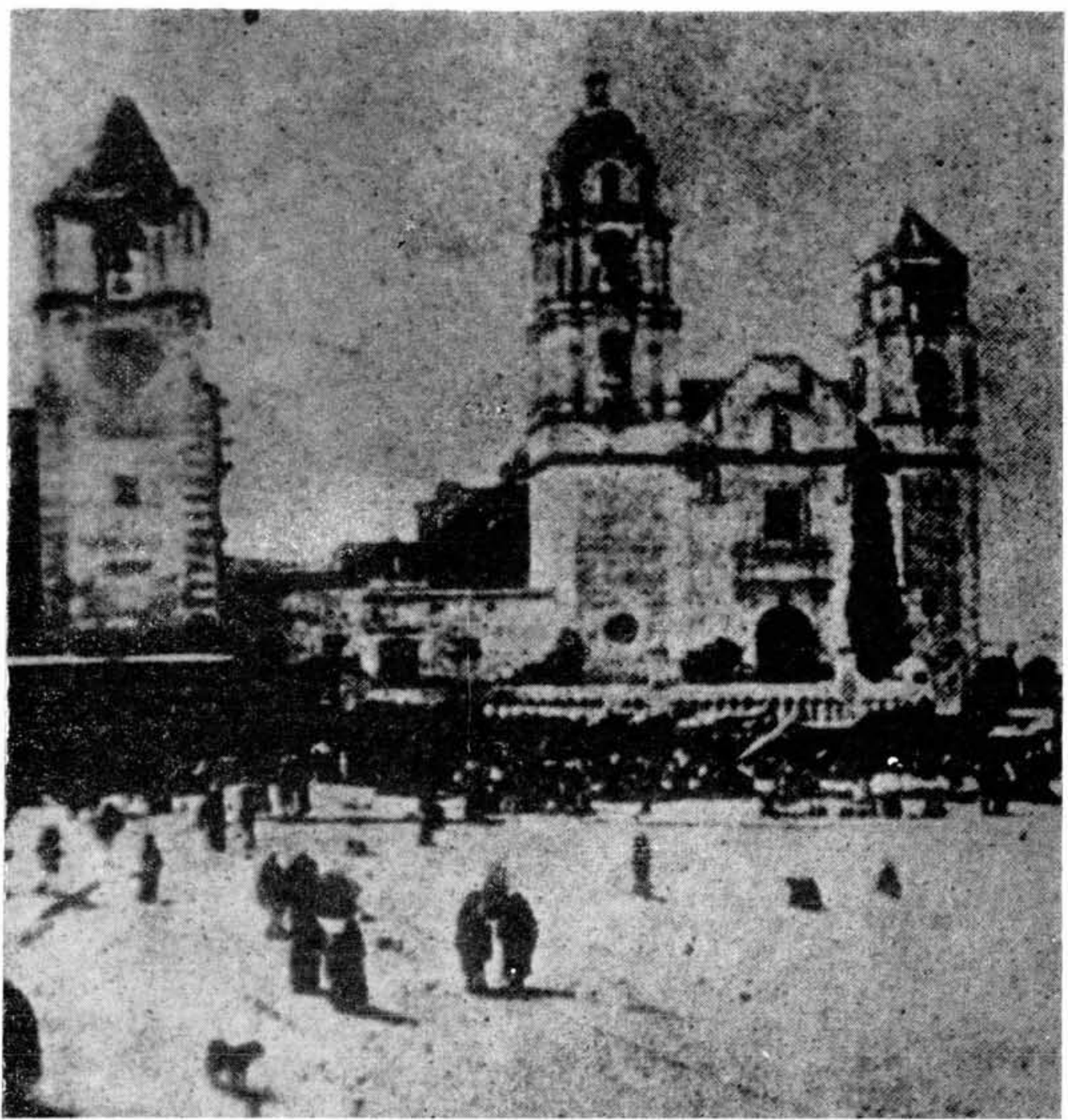

Figura 1. San Miguel de Allende. La parroquia según una fotografía del siglo xix. 
DOI: http://dx.doi.org/10.22201/iie.18703062e.1986.55.1271

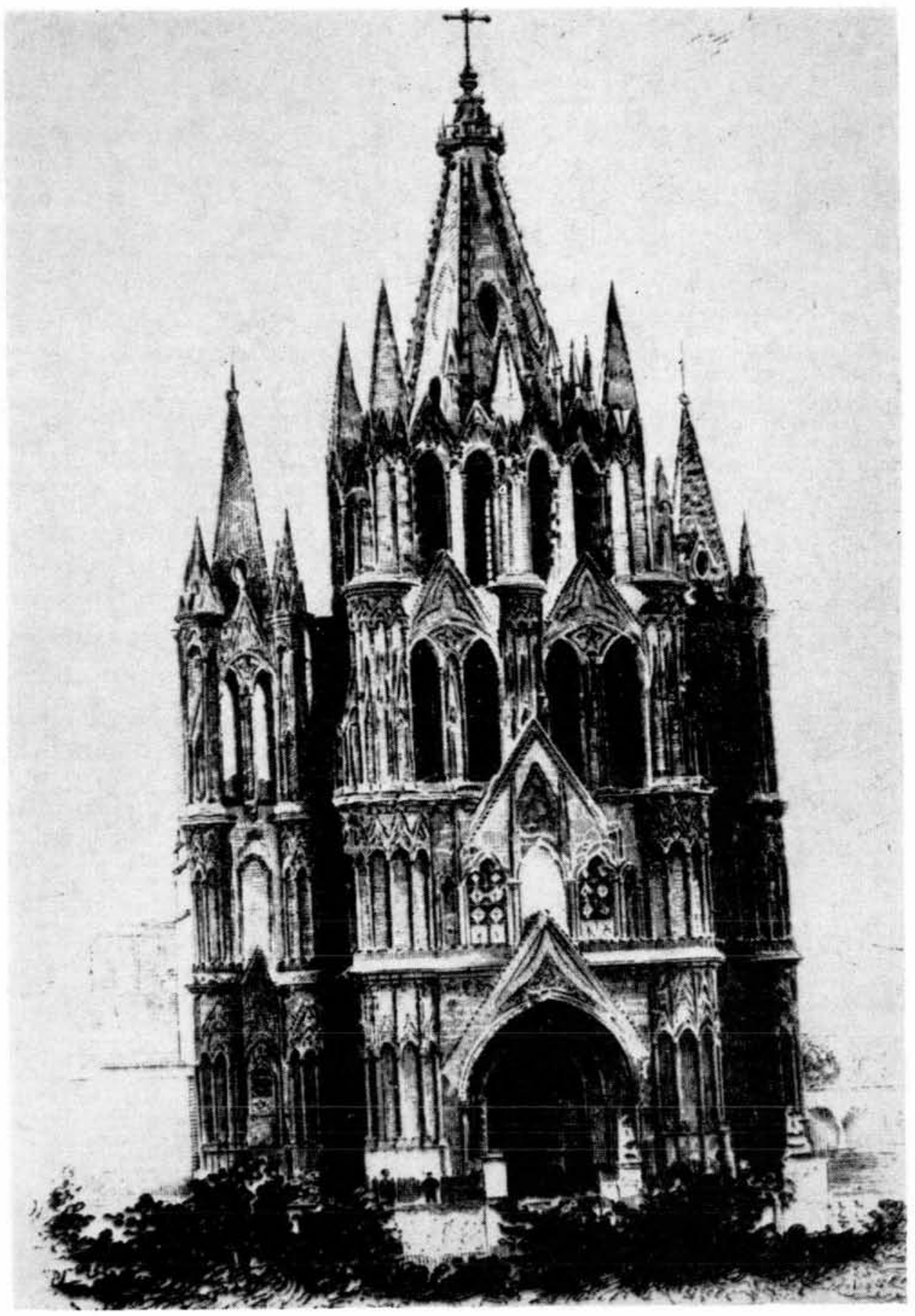

Figura 2. San Miguel de Allende, La parroquia. Litografía del siglo xix. 
de mayor a destajo .... se da por entregado y pagado y de ellos otorga carta de pago y recibo en toda forma ... ${ }^{24}$

Según parece, la única escultura de la fachada que se salvó fue la de San Miguel, con ciertas reservas podríamos decir que es la misma que hoy aparece en la renovación que se hizo a fines del siglo pasado.

El interior de la iglesia conserva la traza de su autor, planta de una sola nave en forma de cruz latina, en cuyo crucero se desplanta la cúpula sobre tambor octogonal; presbiterio de planta rectangular, que debió haber ostentado un magnífico retablo barroco al igual que los colaterales que ya no existen, pues la moda neoclásica se encargó de sustituirlos en el siglo pasado. De la Maza nos habla de pinturas de Miguel Cabrera y de los Rodríguez Juárez, algunas de éstas todavía se conservan en la sacristía.

De las capillas laterales no nos ocuparemos, pues Francisco de la Maza, en su obra sobre esta ciudad nos habla explícitamente de ellas, y porque además no nos consta que hayan formado parte de la traza original, pues Sobrarias nunca las mencionó al formar la planta.

De los últimos trabajos que se hicieron en esta parroquia en el siglo xviIr, mencionaremos una capilla tras el altar principal, la cual está sobre una cripta sepulcral de bóveda plana, atribuida al arquitecto Tresguerras. ${ }^{25}$

Para dar por terminado nuestro trabajo hacen falta algunas palabras acerca del estilo artístico que privó en la arquitectura de este templo: la planta no se alejó del estilo renacentista, en cambio en su alzado se distinguen signos de un barroquismo sobrio, así lo determinó Sobrarias, cuando dijo que la obra fuese llana ". . . sin mucho adorno de portadas, cornisamentos y adorno de toda ella.." "26

De la fachada del siglo xvir tan sólo conocemos el acceso al templo: un arco de medio punto y su entablamento, lo demás lo inferimos por un documento gráfico antiguo que publicó De la Maza, ${ }^{27}$ en el cual se alcanza a distinguir un sobreentablamento en el que descansa la ventana adintelada del coro, en cuyos flancos se ven dos nichos, seguramente con las figuras apostólicas de San Pedro y San Pablo; remata la composición un frontón semihexagonal, en el centro de éste se aprecia un tercer nicho

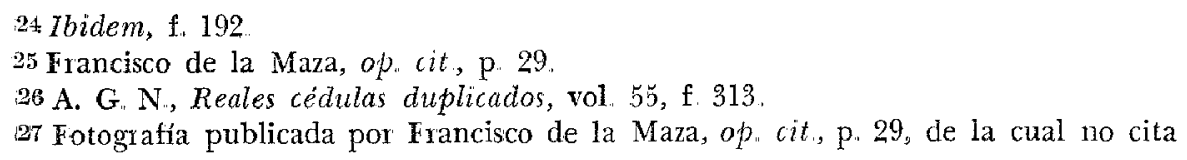
filente. 
que debió albergar la imagen del arcángel Miguel, advocación de la iglesia y patrono del lugar. Dos torres desiguales enmarcaban aquella fachada, visión de la que nos privó el cantero Zeferino Gutiérrez al darle esa fisonomía que ahora le conocemos, misma que nos presenta una imagen falsa, muy distinta del vocabulario que se traduce en su interior. Es verdaderamente una lástima, que todos cuantos conocen esta iglesia, tan sólo recuerclen la fachada pseudo-gótica que vino a opacar el sencillo monumento del arte dieciochesco. 